\title{
Brain-Specific PolyA- Transcripts Are Detected in PolyA+ RNA: Do Complex PolyA- Brain RNAs Really Exist?
}

\author{
Brenda P. Fung, ${ }^{1}$ Murray H. Brilliant, ${ }^{a}$ and Dona M. Chikaraishi ${ }^{1,2}$ \\ 'Neuroscience Program and 'Department of Neurology and Neurosurgery, Tufts University School of Medicine, Boston, \\ Massachusetts 02111
}

Transcripts encoded by 2 different rat genomic clones, $\mathrm{rg} 13$ and rg 100, appear to be typical brain-specific polyA - RNAs, as defined by previous criteria (rare, polysomal, and postnatally expressed from single-copy genes). However, we have found by using a sensitive nuclease protection assay that low levels of these iranscripts $(10 \%$ and $3 \%$, respectively) are detected in polyA + RNA. To determine if rg transcripts that fractionate as polyA- could have resulted from nicking of polyA + RNA, we assessed the integrity of 2 known polyA + RNAs, those of tyrosine hydroxylase, a 2-kilobase (kb) mRNA, and sodium channel, a 9.5-kb RNA. Using RNA prepared by several different procedures, including $\mathrm{LiCl}$-urea and guanidine thiocyanate followed by $\mathrm{CsCl}$ centrifugation, the shorter message fractionated as polyA+ after 2 cycles over oligodeoxythymidine (oligo-dT) cellulose, whereas the majority of the longer sodium channel RNA fractionated as polyA, as assayed by nuclease protection using probes from the 5' end of the 2 genes. However, on Northern blots, the same RNA preparations showed an intact 9.5-kb sodlum channel band only in polyA + RNA, suggesting that the polyARNAs were randomly cleaved, resulting in a smear of sizes that could not be detected as a discrete band. These data imply that long messages may be nicked during standard isolation procedures and that this would not be detected by Northern blot analysis. Therefore, we conclude that, though rg transcripts could be synthesized in both poly $A^{+}$and poly $A^{-}$ forms or deadenylated through a regulated metabolic process, it is likely that the so-called brain polyA- mRNAs are actually labile, brain-specific polyA+ RNAs that lose their polyA tails during isolation. This class of labile RNAs is expressed beginning around the time of birth.

Gene expression in the mammalian brain is characterized by a large diversity of high-complexity transcripts. Saturation hybridization studies have shown that at least 1.5 to 2 times more of the unique-sequence portion of the genome is transcribed in the brain compared to other tissues, when examined at either

\footnotetext{
Received May 4, 1990; revised Sept. 4, 1990; accepted Oct. 17, 1990.

This work was supported by U.S. Public Health Service Grants GM10689 to B.P.F. and GM33991 to D.M.C. from NIH. We thank Drs. Sharon Cooperman and Gail Mandel for providing the sodium channel clone and fractionated RNA samples; Drs. Terri Wood and Allan Tobin for fractionated RNA samples; Cathy B. Hamilton for samples of rat heart, lung, and spleen RNA; and Barbara D'Angelo for aid in preparation of the manuscript.

Correspondence should be addressed to Dona M. Chikaraishi, Ph.D., Neuroscience Program, Tufts University School of Medicine, 136 Harrison Avenue, Boston, MA 02111 .

a Present address: Fox Chase Cancer Center, Philadelphia, PA 19111. Copyright (C) 1991 Society for Neuroscience 0270-6474/91/110701-08\$03.00/0
}

the nuclear or the polysomal RNA levels in many organisms (rat, mouse, rabbit, sheep, squid, and goldfish; Hahn and Laird, 1971; Brown and Church, 1972; Grouse et al., 1972, 1978a,b; Church and Schultz, 1974; Bantle and Hahn, 1976; Chikaraishi et al., 1978; Kaplan et al., 1978; Grady et al., 1979, 1981; Lee et al., 1979; Van Ness et al., 1979; Deeb, 1983; Hitti and Deeb, 1984; Kaplan and Gioio, 1986; Perrone Capano et al., 1986). The mRNA complexity of the rodent brain has been estimated to be between 2.3 and $3.6 \times 10^{8}$ nucleotides, which is enough information to encode 125,000-180,000 different 2-kilobase (kb) mRNAs (Chikaraishi, 1979; Van Ness et al., 1979; Chaudhari and Hahn, 1983). The majority of the diverse transcripts found in the mammalian brain fall into a rare class present at about 0.01-1 copy per cell (Bantle and Hahn, 1976; Chikaraishi, 1979). In a survey of rat brain cDNA clones, Milner and Sutcliffe (1983) found that the less abundant transcripts tended to be longer and brain specific. Of the rarest brain-specific RNAs identified, the average size was nearly 5000 nucleotides. Rare transcripts may be RNAs that are actually abundantly expressed in a small number of specific cells. For example, the enzyme tyrosine hydroxylase is found only in catecholaminergic neurons in the CNS. In these cells, tyrosine hydroxylase RNA is moderately abundant (200-500 copies per cell); however, its concentration in total brain mRNA is diluted to less than 1 copy per cell, making tyrosine hydroxylase RNA a low abundance or "rare" message when averaged over the entire brain (Chikaraishi et al., 1983; M. Chikaraishi, unpublished observations).

Complexity mcasurements of rodent brain cytoplasmic RNAs indicated that half were nonpolyadenylated (Chikaraishi, 1979; Van Ness et al., 1979). Some known eucaryotic mRNAs, such as certain histone sequences, lack polyA tails almost entirely (Adesnik and Darnell, 1972), while other genes, such as those for $\beta$-actin (Hunter and Garrels, 1977; Kaufmann et al., 1977; Morrison et al., 1979), casein (Houdebine, 1976; Nadin-Davis and Mezl, 1983), protamine (Gedamu and Dixon, 1976), and $\alpha$-lactalbumin (Nadin-Davis and Mezl, 1983), give rise to both poly $\mathrm{A}^{+}$and poly $\mathrm{A}^{-}$isoforms. Both poly $\mathrm{A}^{+}$and polyA RNAs can be translated in vitro (Kaufmann et al., 1977; Chikaraishi, 1979; Morrison et al., 1979; Hahn et al., 1983). These studies indicate that the bimorphic species represent the more abundant RNAs. However, the brain appears to be the only tissue in which a large diversity of rare poly $\mathrm{A}^{-}$transcripts has been described.

Two types of saturation hybridization experiments have suggested that the majority of brain poly $A^{-}$mRNAs comprise a set of sequences different from those encoded by polyA+ RNAs. First, polyA ${ }^{+}$mRNA from the adult rat brain saturated only half of those single-copy DNA sequences saturated by total cytoplasmic RNA, and when excess polyA- RNA was then added 
to the polyA $\mathrm{A}^{+} \mathrm{mRNA}$ hybridization, the remaining $50 \%$ of the total complexity was recovered (Chikaraishi, 1979). Second, using saturation hybridization both to single-copy mouse DNA and to cDNA made from polyA ${ }^{-}$RNA, Hahn and colleagues showed that mouse brain polysomal polyA ${ }^{-}$mRA had few sequences in common with the polyA ${ }^{+}$mRNA fraction and thus constituted a nonoverlapping class of complex brain mRNAs (Van Ness et al., 1979). In contrast, the polyA- scquences dcrived from mouse liver (Bantle et al., 1980) or mouse kidney (Ouellette and Ordahl, 1981) were completely overlapping with the polyA ${ }^{+}$population. Further studies showed that the expression of the nonpolyadenylated class of mRNA begins around the time of birth and reaches adult levels by about 6 weeks of age in the mouse brain (Chaudhari and Hahn, 1983; Hahn et al., 1983). In contrast, the bulk of polyA InRNAs is already present at birth, again implying that the poly $A$ and poly $\mathrm{A}^{+}$ sequences may be distinct.

The existence of true polyA $A^{-}$mRAs in brain has been controversial. To date, there has been no report of a full-length poly $\mathrm{A}^{-}$clone for which the $3^{\prime}$ and $5^{\prime}$ ends have been determined. However, fragments of several brain-specific putative polyA genes were identified from a genomic library of rat uniquesequence DNA (Brilliant et al., 1984). We show here that 2 different transcripts, typical of those previously termed polyA mRNAs [brain specific, rare in abundance, postnatally expressed, and not retained on oligodeoxythymidine (oligo-dT) columns], are detected in low amounts as polyA+ RNA. When the same RNA preparations were examined for the relative distribution of a long poly $\mathrm{A}^{+}$message, that of the type II sodium channel of rat, the 5 sodium channel sequences were also more abundant in polyA RNA prepared by a variety of methods, suggesting that brain messages of this size class $(9.5 \mathrm{~kb})$ may be easily nicked during isolation. Thus, while we cannot rule out bimorphism or a metabolic cleavage event, it is likely that poly $\mathrm{A}^{-}$ mRNAs may actually represent the $5^{\prime}$ ends of rare brain-specific poly $A^{+} m$ RNAs that have become separated from their corresponding polyA $\mathrm{A}^{+}$tails.

\section{Materials and Methods}

Preparation of RNAs. Unless otherwise indicated, tissues were from Sprague-Dawley rats at 2 months of age. Several RNA isolation protocols were used: (1) Total RNA from cells or tissues was extracted with 5 m guanidine thiocyanate, $1 \%$ sodium $N$-lauryl sarcosine, $25 \mathrm{~mm}$ sodium citrate $(\mathrm{pH}, 7)$, and $100 \mathrm{~mm} \beta$-mercaptoethanol and purified by centrifugation through $5.7 \mathrm{M} \mathrm{CsCl}$ by the method of Chirgwin et al. (1979). (2) Total RNA from tissues was also prepared by a modification of the method of Auffray and Rougeon (1980): Tissue samples were homogenized in $6 \mathrm{M}$ urea, $3 \mathrm{M} \mathrm{LiCl}, 10 \mathrm{~mm}$ vanadyl ribonucleoside complex (VRC; BRL or Life Sciences Corp.) with a Brinkman Polytron at high speed, using $10 \mathrm{ml}$ homogenization solution per gram of tissue. The mixture was sonicated for 30-60 sec to shear the DNA and held on ice for $12-18 \mathrm{hr}$. RNA was pelleted at $6000-8000 \times \mathrm{g}$ for $8-10 \mathrm{~min}$, resuspended in $10 \mathrm{~mm}$ Tris $(\mathrm{pH}, 7.5), 10 \mathrm{~mm}$ EDTA, and $0.2 \%$ SDS, extracted 2-4 times with equal volumes of phenol: chloroform : isoamyl alcohol (25:24:1) containing 8-hydroxyquinoline, extracted once with chloroform, and ethanol precipitated. (3) Total RNA was extracted as in protocol 2, except that VRC and sonication were omitted and the RNA-containing pellets were resuspended directly in several $\mathrm{ml}$ of 30 $\mathrm{mm}_{\mathrm{M}}$ Tris $(\mathrm{pH}, 7.4), 1 \mathrm{~mm}$ EDTA, $0.15 \mathrm{M} \mathrm{NaCl}$, and $1 \%$ SDS containing $400 \mu \mathrm{g} / \mathrm{ml}$ predigested proteinase K (Boehringer-Mannheim; see Ilaria et al., 1985; Shackleford and Varmus, 1987). Following proteinase K digestion for $30-60 \mathrm{~min}$ at $37^{\circ} \mathrm{C}$, RNA was extracted and precipitated as above. (4) VRC and sonication were omitted, and RNA pellets were resuspended in RNA buffer as in protocol 2 , immediately phenol-chloroform extracted, and the aqueous phase was then treated with proteinase $\mathrm{K}$; organic extraction and ethanol precipitation followed. Several other RNA isolation methods were also tested, including the use of guanidine hydrochloride and guanidine-lithium; similar results were obtained in preliminary tests.

Two-cycle purified polyA ${ }^{+}$and polyA RNAs were prepared by oligodT-cellulose chromatography (type III, Collaborative Rescarch, Inc.; Aviv and Leder, 1972). Quantitation of RNA was by optical density at $260 \mathrm{~nm}$ and by colorimetry following orcinol reaction.

Preparation and labeling of clones $\mathrm{rg} 13, \mathrm{rg} 100, \mathrm{TH}$, and $\mathrm{NaCh}$. Clones $\mathrm{rg} 13$ and $\mathrm{rg} 100$ are independent isolates of a library of phage $\mathrm{M} 13 \mathrm{mp} 7$ containing Sau3A DNA fragments from unique-sequence rat genomic DNA (Brilliant et al., 1984). The rg 13 and rg 100 inserts were subcloned into the EcoRI site of the plasmid vector Sp65, which contains a promoter for Sp6 RNA polymerase. Appropriate subclones were linearized with BamHI, and labeled cRNA was synthesized from the Sp6 promoter using $\alpha{ }^{32} \mathrm{P}$-UTP $(800 \mathrm{Ci} / \mathrm{mMol}$; New England Nuclear) according to the supplier's protocol (Promega). The labeled cRNA had an estimated specific activity of $3-10 \times 10^{8} \mathrm{cpm} / \mu \mathrm{g}$, which was approximately $10-$ fold greater than that achieved by end-labeling of DNA insert fragments (Brilliant et al., 1984).

Clone TH (pAA.360) represents sequences from the $5^{\prime}$ end of the rat tyrosine hydroxylase gene inserted into an Sp6 vector. It contains 168 nucleotides of 5' flanking sequences, 125 nucleotides comprising exon 1 , and 71 nucleotides of adjacent sequences from intron 1 .

Clone $\mathrm{NaCh}$ contains 188 nucleotides of the $5^{\prime}$ untranslated and coding sequences of the rat sodium channel type II gene (Cooperman et al., 1987). Labeled cRNA was synthesized from an Sp6 promoter as above, to a similar specific activity.

Nuclease protection using RNA probes. Full-length labeled cRNA was gel purified from $6 \%$ or $8 \%$ polyacrylamide $/ 8 \mathrm{M}$ urea denaturing gels by passive elution from gel pieces in $0.5 \mathrm{M}$ ammonium acetate, $10 \mathrm{~mm}$ Tris (pH, 7.5), $1 \mathrm{~mm}$ EDTA, and $0.1 \%$ SDS for $3-18 \mathrm{hr}$ at $37^{\circ} \mathrm{C}$, with gentle agitation. Gel-purified probe $(0.03$ to $0.07 \mathrm{ng} ; 0.1-0.2 \mathrm{pmol})$ was coprecipitatcd with appropriatc RNA samples, plus $E$. coli $t$ RNA if necessary to equalize the total RNA content per reaction tube. The RNA pellets were resuspended in $20 \mu$ of hybridization solution $[72 \%$ formamide (BRL Ultrapure), $40 \mathrm{~mm}$ PIPES (pH, 6.8), $1 \mathrm{~mm}$ EDTA, $0.4 \mathrm{M} \mathrm{NaCl}$ ], overlaid with mineral oil, heated in boiling water for 3 min, and hybridized for $16-20 \mathrm{hr}$ at $50^{\circ} \mathrm{C}$. Each mixture was diluted with $200 \mu \mathrm{l}$ nuclease digestion buffer $[0.3 \mathrm{M} \mathrm{NaCl}, 10 \mathrm{mM}$ Tris $(\mathrm{pH}$, 7.5), $2 \mathrm{~mm}$ EDTA containing $40 \mu \mathrm{g} / \mathrm{ml}$ RNaseA (Sigma or BoehringerMannheim)], vortexed, centrifuged briefly, and transferred to a fresh tube. Digestion was performed for $2 \mathrm{hr}$ at room temperature and was terminated by addition of $200 \mu \mathrm{l}$ phenol-chloroform. Following phenolchloroform and chloroform extractions, the RNAs were ethanol precipitated in the presence of carrier $t \mathrm{RNA}$, and the nuclease-resistant RNA species were displayed on $8 \%$ polyacrylamide $/ 8 \mathrm{M}$ urea denaturing gels run in $0.09 \mathrm{M}$ Tris-borate $(\mathrm{pH}, 8.3)$. Most autoradiographic exposures were for $16-48 \mathrm{hr}$.

Relative quantitation of protected hands. The signal strength in the protected bands is proportional to the amount of homologous RNA in the preparation and the specific activity of the cRNA probe. Because an excess of the same probe was hybridized to equivalent amounts of the various RNA samples, relative quantitation of homologous transcripts within an experiment can be determined by densitometric scan. ning of the protected RNA band from the autoradiogram.

Northern analysis. RNA samples were electrophoresed on a $0.6 \%$ agarose gel containing formaldehyde (Lewis et al., 1983) and transferred onto a nylon membrane (Nytran, Schleicher, and Schuell) by capillary action overnight. The membrane was incubated with $1-2 \times 10^{6} \mathrm{cpm} /$ ml labeled sodium channel $(\mathrm{NaCh}) \mathrm{cRNA}$ in the presence of total liver RNA (as compctitor to climinatc crossing of the probe with ribosomal RNA; see Cooperman et al., 1987), in 50\% formamide, $5 \times$ SSPE (1 $\times$ SSPE $=0.15 \mathrm{M} \mathrm{NaCl}, 10 \mathrm{mM} \mathrm{NaH}_{2} \mathrm{PO}_{4}, 1 \mathrm{~mm}$ EDTA, pH, 7.4), $0.2 \%$ SDS, $2 \mathrm{~mm}$ Na pyrophosphate, $200 \mu \mathrm{g} / \mathrm{ml} t \mathrm{RNA}$, and $400 \mu \mathrm{g} / \mathrm{ml}$ heparin at $65^{\circ} \mathrm{C}$, and washed to $0.1 \times \mathrm{SSC}(1 \times \mathrm{SSC}=0.15 \mathrm{M} \mathrm{NaCl}, 0.015 \mathrm{M}$ $\mathrm{Na}$ citrate, $\mathrm{pH}, 7.0$ ) with $0.1 \% \operatorname{SDS}$ at $65^{\circ} \mathrm{C}$.

\section{Results}

Transcripts of clones rg13 and rg100 have the characteristics of putative poly $A^{-}$brain-specific RNAs: brain specificity and postnatal expression. To test RNA prepared from various tissucs for the presence of $\mathrm{rg}$ transcripts, we used nuclease protection assays previously determined to be sensitive to the level of 0.1 0.01 copy per cell (Brilliant et al., 1984; data not shown). Figure 1 shows that rgl00 transcripts are only found in the brain (for 


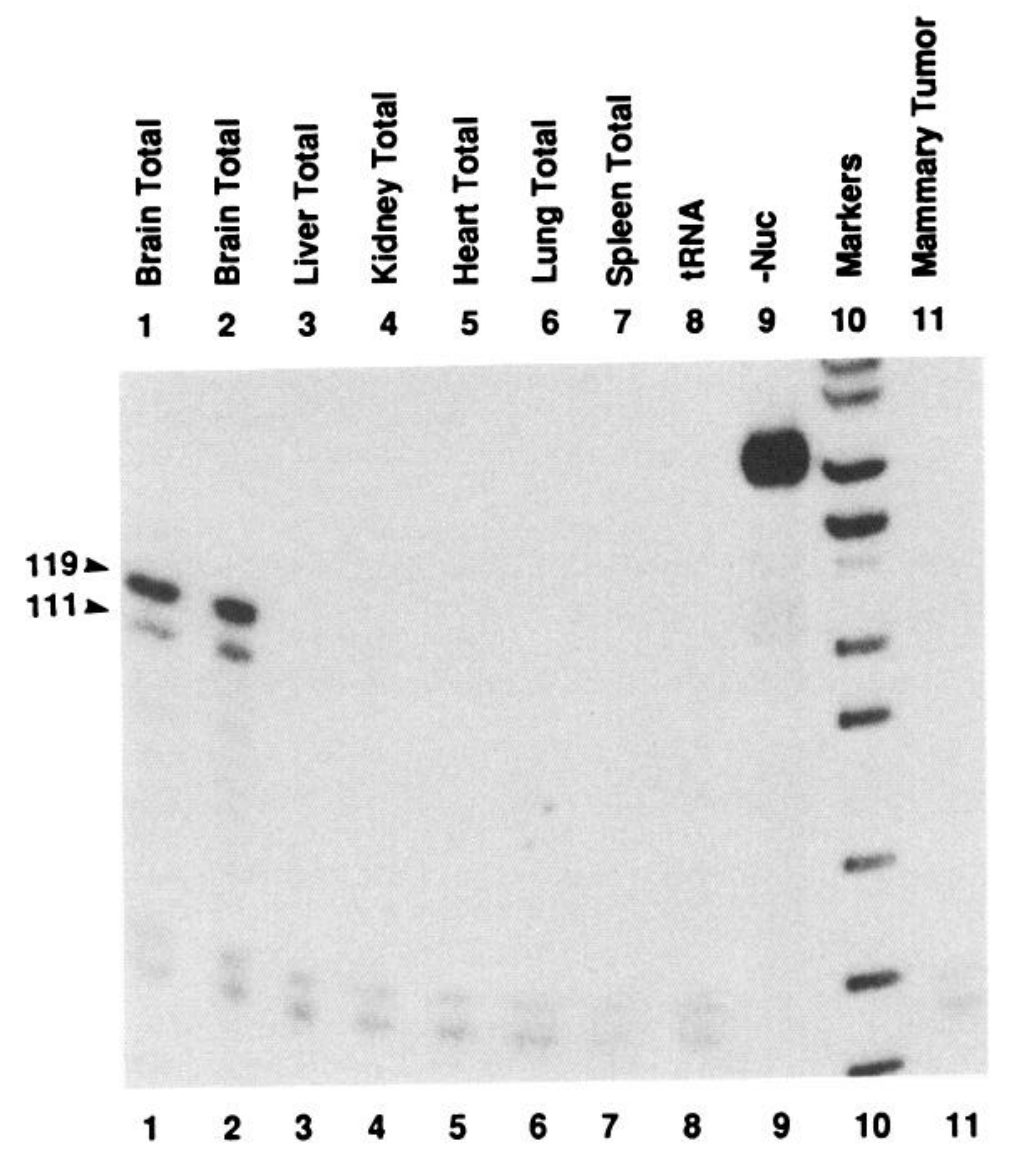

Figure 1. Expression of $\mathrm{rg} 100$ is brain specific. The typical pattern of $\mathrm{rg} 100$ expression in various tissues, as revealed by nuclease protection, is shown. Uniformly labeled $\mathrm{rg} 100$ cRNA probe was annealed to $50 \mu \mathrm{g}$ total RNA from the indicated sources. All tissues were from adult rats. Total RNA in lanes 1 , $3-7$, and 11 were prepared by protocol 2 (see Materials and Methods); RNA used in lane 2 was prepared by protocol 3 . Based on the nucleotide sequence of the $\mathrm{rg} 100$ insert, a protected band of 111 nucleotides is expected; however, if the RNase A did not accurately clip the probe at the end of the $\mathrm{rg} 100$ insert, cutting at the next pyrimidine tract would give rise to a 119-nucleotide labeled fragment. With additional digestion, smaller bands appear (e.g., at 93 nucleotides; see Figs. 2, 3), reflecting promiscuous RNase cuts at the AT-rich $3^{\prime}$ end of the duplex molecule. The lower bands in this figure are nonspecific, because they also appear in the sample containing E. coli $t$ RNA (lane 8). Lane 9 , $\mathrm{rg} 100$ probe without nuclease digestion. Size markers in lane 10 are, from the top, 190,180,160,147, 123,110, 90,76 , and 67 nucleotides.

rg13, see Brilliant et al., 1984). Radioactively labeled $\mathrm{rg} 100$ antisense sequences are protected by total cellular RNA from whole rat brain (lanes 1,2 ), but not by RNA from non-neural tissues such as liver, kidney, heart, lung, spleen, or a mammary tumor (lanes 3-7, 11). Both rg transcripts were present in pelleted polysomes prepared from brain (data not shown). Previously, $\mathrm{rg} 13$ transcripts were shown to be present at an average of 2.7 copies per adult rat brain cell (Brilliant et al., 1984); by comparison, we estimate the abundance of rgl00 transcripts to be about 1 copy per cell.

Because the expression of poly $A^{-}$mRNAs as a class appears to be primarily postnatal in both the mouse brain (Chaudhari and Hahn, 1983) and the rat brain (M. H. Brilliant, unpublished observations), we investigated the time course of expression of $\mathrm{rg} 13$ and $\mathrm{rg} 100$. Transcripts of clone $\mathrm{rg} 100$ are present at very low levels at embryonic day 17 (E17) and increase with developmental age (Fig. $2 A, C$ ). The adult level of $\mathrm{rg} 100$ is $8-10$-fold that at E17, with most of the increase occurring between E20 and postnatal day 10 (P10). The expression of clone rg13 (Fig. $2 B, C)$ appears to be slightly greater at E17 than at E20 (1.5-3fold enrichment at E17, using the same RNA preparations that showed little embryonic rg 100 gene expression). Again, by P10, $80 \%$ of the adult level of transcript is present, suggesting that rg13 and rg100 may be under similar, but slightly different, temporal programs. These data show that the patterns of $\mathrm{rg} 100$ and rg 13 expression agree with the previous observations that most poly $\mathrm{A}^{-}$transcripts of the complex class appear postnatally.

Thus, by previously established criteria for the class of highcomplexity brain-specific polyA- mRNAs, transcripts of both rg13 and rg100 appear to be typical of this class: They are rare in abundance, brain specific, and appear primarily after birth. Southern blot analysis shows that they both represent singlecopy genes (data not shown).

Are rg100 and rg13 transcripts long polyA ${ }^{+}$RNAs? To evaluate directly the percentage of $\mathrm{rg}$ transcripts found in poly $\mathrm{A}^{+}$versus polyA- RNA, RNA extracted from equivalent amounts of tissue were compared. For example, because $2 \%$ of total RNA is polyA ${ }^{+}$, $50 \mu \mathrm{g}$ total or polyA- RNA is equivalent to $1 \mu \mathrm{g}$ poly $\mathrm{A}^{+} \mathrm{RNA}$.

When poly $\mathrm{A}^{+}$and poly $\mathrm{A}^{-}$RNA derived from equivalent amounts of tissue were assayed, the $\mathrm{rg} 100$ and $\mathrm{rg} 13$ transcripts were found only in the polyA- fraction (Fig. $3 A$, lanes 5 and 6 ; $B$, lanes 1 and 3 ). This was true for more than 10 different preparations of brain RNA. However, when a 10 - or 20 -fold excess of polyA ${ }^{+}$brain RNA was assayed using a sensitive cRNA probe (which can be labeled to a higher specific activity than an end-labeled DNA probe used previously; Brilliant et al., 1984), transcripts of both $\mathrm{rg} 100$ and $\mathrm{rg} 13$ could be readily detected in the poly $\mathrm{A}^{+}$fraction (Fig. $3 A$, lane $7 ; B$, lane 2 ). Densitometric measurements from several experiments indicate that $3 \%$ of $\operatorname{rg} 100$ and $10 \%$ of $\operatorname{rg} 13$ sequences are found in the poly $\mathrm{A}^{+}$ fraction of brain RNA. In contrast, sequences corresponding to the $5^{\prime}$ end of rat tyrosine hydroxylase, a $2-\mathrm{kb}$ polyA $\mathrm{A}^{+}$message, were found exclusively in the poly $\mathrm{A}^{+}$fraction of brain RNA (Fig. 3C).

In a typical experiment in which the polyA ${ }^{+}$RNA fraction was passed over oligo-dT cellulose a third time, $17.6 \%$ of the RNA was not retained on the column, representing either the $5^{\prime}$ ends of newly nicked polyA ${ }^{+}$molecules or contaminating nonpolyadenylated molecules. If the nuclease protection signals seen in the polyA ${ }^{+}$fractions (Fig. $3 A$, lane $7 ; B$, lane 2 ) were 
A. $\mathbf{r g} 100$

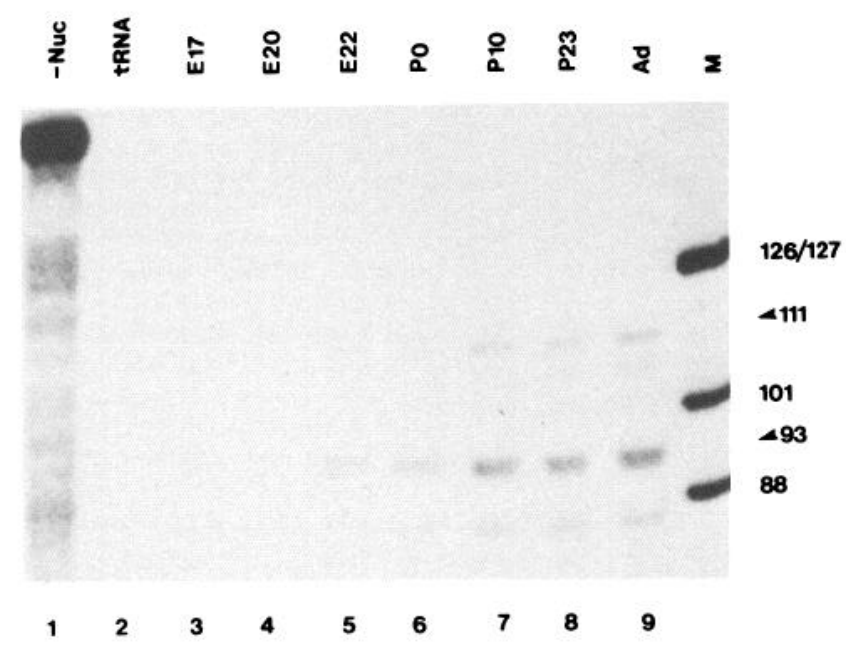

B. $\operatorname{rg} 13$

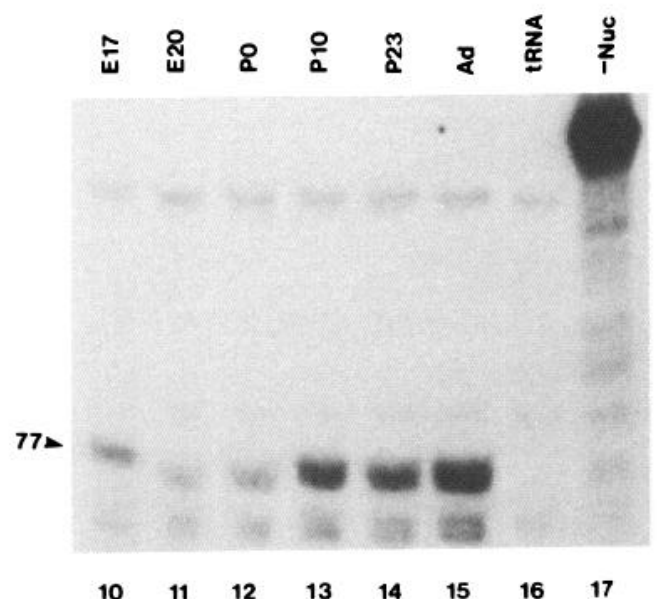

$\begin{array}{llllllll}10 & 11 & 12 & 13 & 14 & 15 & 16 & 17\end{array}$

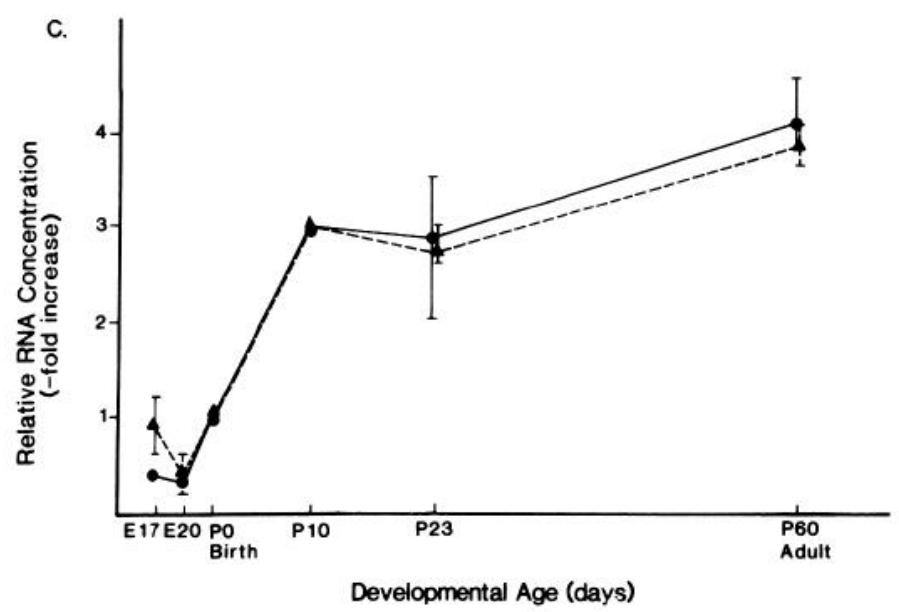

Figure 2. Expression of $\mathrm{rg} 100$ and $\mathrm{rg} 13$ transcripts at various developmental ages. Nuclease protection of $\mathrm{rg} 100$ and $\mathrm{rg} 13$ sequences was due solely to contaminating polyA- molecules, then those intensities should correspond to $1.76 \mu \mathrm{g}^{\text {polyA }}-\mathrm{RNA}(17.6 \%$ of $10 \mu \mathrm{g})$. However, the signal observed was at least $8-10$-fold greater than would be expected from $1.76 \mu \mathrm{g}$ polyA- RNA. If part of the $17.6 \%$ of nonretained RNAs were due to nicked molecules (which is undoubtedly true), an even smaller amount of the polyA ${ }^{+}$signal would be attributable to contaminating polyA- RNAs. In a direct measure of possible poly $A^{-}$contamination of the poly $\mathbf{A}^{+}$fraction, labeled antisense RNA was mixed with a sample of total RNA and passed twice over oligo-dT. Less than $0.07 \%$ of the label fractionated with the polyA+ $\mathrm{ANAs}^{+}$ indicating that cross-contamination is minimal.

Because both $\mathrm{rg}$ transcripts can be detected in the polyA $\mathrm{A}^{+}$ fraction if sufficient amounts of RNA are used, did their presence in the poly $\mathrm{A}^{-}$fraction result from cleavage of poly $\mathrm{A}^{+} \mathrm{RNAs}$ ? If brain-specific RNAs tend to be longer than the average, as suggested by Milner and Sutcliffe (1983), they may be readily nicked during isolation, such that many molecules lose their polyA tails and therefore partition into the poly $\mathrm{A}^{-}$fraction.

To address this question, we examined the partitioning pattern for a known polyA $\mathrm{A}^{+}$message that is considerably longer than the average. We chose the sodium channel type II message, which is found in moderately high amounts in rat brain and is $9.5 \mathrm{~kb}$ in length (Noda et al., 1986; Cooperman et al., 1987). The probe used to detect this message represents a sequence at the $5^{\prime}$ end of the transcript. Nuclease protection assays (Fig. 4) show that similar results were obtained for $\mathrm{Na}^{+}$channel as for the rg clones: When total, polyA ${ }^{+}$or polyA- RNAs from equivalent amounts of tissue were compared, more transcripts were found in the polyA- fraction of RNA than in the poly $\mathrm{A}^{+}$fraction. Densitometric analysis showed that at least $90 \%$ of $\mathrm{Na}^{+}$channel messages partitioned into the poly $\mathrm{A}^{-}$fraction, with $4-10 \%$ surviving as poly $\mathrm{A}^{+}$after 2 rounds of oligo-dT selection.

Several RNA preparations were examined to determine if different isolation methods generated more intact RNA. Figure 4 shows the results of nuclease protection using fractionated RNA obtained by 2 of the isolation methods tested in our laboratory, as well as RNA isolated and fractionated by 2 other individuals, using methods routine to them. These methods include guanidine denaturation with or without subsequent $\mathrm{CsCl}$ centrifugation, and lithium-urea denaturation (see Materials and Methods). Similar results were obtained with all of the RNA preparations. Interestingly, these RNA preparations gave the expected pattern of message distribution by Northern blot analysis, the usual method for assessing RNA quality (Fig. 5; Cooperman et al., 1987). The sodium channel probe detected a discrete $9.5-\mathrm{kb}$ RNA species in total brain RNA and in polyA ${ }^{+}$

performed using cRNA probes annealed to $50 \mu \mathrm{g}$ of total cellular brain RNA taken at the indicated developmental times. $A, \operatorname{rg} 100$ : lane 1, no nuclease digestion; lane 2, E. coli tRNA $(50 \mu \mathrm{g})$; lane 3, E17; lane 4, E20; lane 5, E22/birth (pups were taken by cesarian section before birth; normal gestation period is 21-22 d); lane 6, P0 (killed less than $18 \mathrm{hr}$ after birth); lane $7, \mathrm{P} 10$; lane $8, \mathrm{P} 23$; lane 9 , adult (8 weeks); $M$, size markers. The major protected bands, at 111 and 93 nucleotides, are indicated. B, rg13: lane 10, E17; lane 11, E20; lane 12, P0 (less than 3 $\mathrm{hr}$ after birth); lane 13, P10; lane 14, P23; lane 15, adult; lane 16, $t \mathrm{RNA}$ $(50 \mu \mathrm{g})$; lane $17, \mathrm{rg} 13$ probe without nuclease digestion. The major protected band at 77 nucleotides is indicated. $C$, Graph of the relative increase in concentration of rg100 transcripts (solid line) and rg13 transcripts (broken line) normalized to the amount present at birth $(P 0)$. Each data point is the result of 2 or more experiments. 


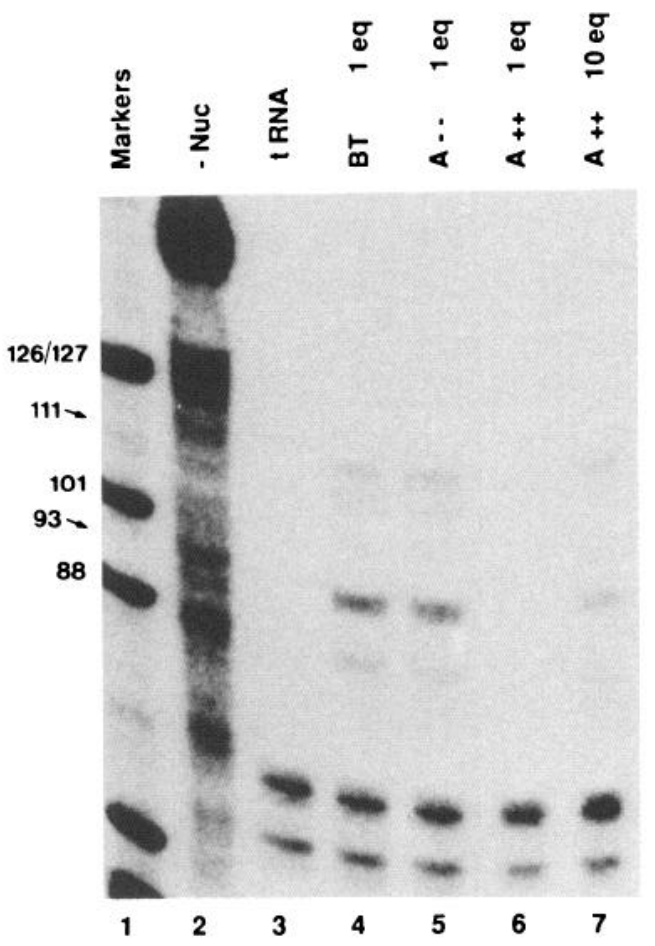

B. $r g 13$

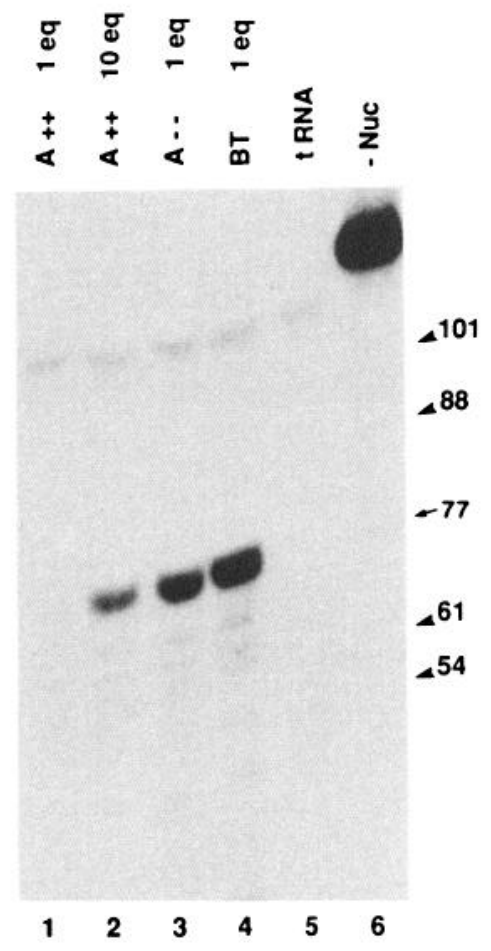

C. TH

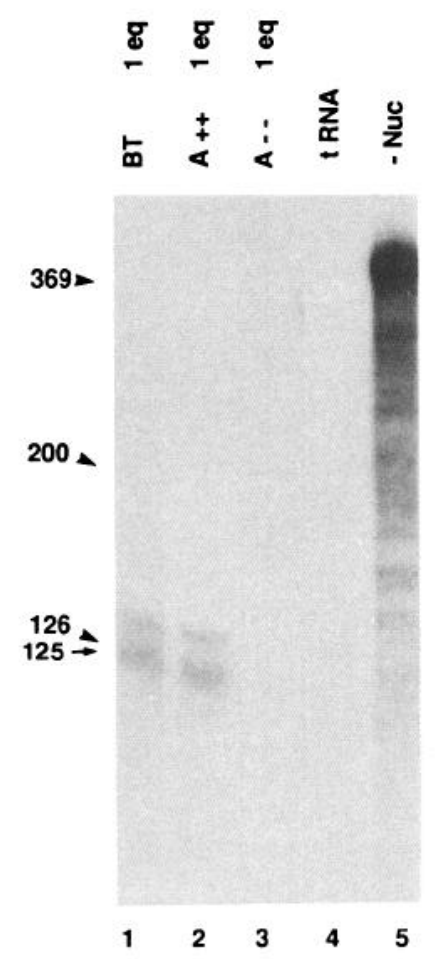

Figure 3. rg Sequences are present in polyA ${ }^{+}$RNA. cRNA probe corresponding to $\mathrm{rg} 100(A), \operatorname{rg} 13(B)$, or tyrosine hydroxylase $(C)$ was annealed to the indicated fractions of RNA and processed for nuclease protection. RNA probe was annealed to $50 \mu \mathrm{g}$ of $E$. coli $t$ RNA (lanes A3, B5, C4), $50 \mu \mathrm{g}$ total RNA from adult rat brain (lanes $A 4$, $B 4, C 1), 50 \mu \mathrm{g}$ polyA- RNA ( 2 cycles over oligo-dT cellulose; lanes $A 5, B 3$, $C 3), 1 \mu \mathrm{g}$ polyA ${ }^{+}$RNA ( 2 cycles; lanes $A 6, B 1, C 2)$, or $10 \mu \mathrm{g}$ poly $\AA^{+}$RNA (2 cycles; lanes $A 7, B 2$ ). All RNA samples were prepared from the same pool of adult rat brain RNA. The amount of RNA in each hybridization reaction was made up to $50 \mu \mathrm{g}$ with $E$. coli $t$ RNA as necessary; in each panel, samples shown are from the same gel. The number of "tissue equivalents" (eq; see text) represented by these amounts of brain RNA are given above each lane. Lanes $A 2$, $B 6, C 5$ : no RNase digestion. Size markers (lane 1 and arrowheads) are indicated; arrows mark the major protected species in each panel. Three-cycle purified polyA ${ }^{+}$RNA in excess gave results equivalent to lane 7 . Substantiation that the signals represent protection of $\mathrm{rg}$ sequences was given by the absence of a signal when a sense-strand rg probe was used (not shown). The protected band in $C$ is 125 nucleotides in size and represents exon 1 of the rat TH gene. 
brain RNA, but not in the polyA- fraction, even though these sequences are clearly present by nuclease protection (Fig. 4). It is apparent from these results that, in our hands as well as others', a significant portion of long poly $\mathrm{A}^{+}$messages is broken during isolation and therefore partitions to the nonpolyadenylated fraction, and that these transcripts are randomly nicked to form an undistinguishing background on a Northern gel.

We conclude from these experiments that long transcripts may be easily broken during isolation. Given that brain expresses a large diversity of rare RNAs, and that the rarer mRNAs tend to be longer and hence more labile, it is not surprising that rg clones could represent regions of long messages that have become separated from their polyA tails during fractionation.

\section{Discussion}

Clones $\mathrm{rg} 13$ and $\mathrm{rg} 100$ were originally isolated as unique-sequence DNA that was transcribed specifically in brain. When RNA from equivalent amounts of tissue was assayed, these transcripts were found exclusively in the polyA- fraction of RNA. However, when excess polyA ${ }^{+}$RNA was assayed, we found that $3 \%$ of $\mathrm{rg} 100$ - and $10 \%$ of $\mathrm{rg} 13$-homologous sequences could be detected in the poly $\mathrm{A}^{+}$fraction of brain RNA. A number of reasons could explain this finding, such as alternative generation of different $3^{\prime}$ ends to give bimorphic species or processing of poly $\mathrm{A}^{+}$transcripts into a more stable (and more abundant) polyA- form. Another possibility is that our clones represent sequences near the $5^{\prime}$ end of long or labile poly $\mathrm{A}^{+}$ RNAs. In this case, nicking during the isolation process would separate the majority of these $5^{\prime}$ sequences from their polyA tails.

When polyA ${ }^{+}$RNA was subjected to Northern blot analysis, we could not detect rg transcripts using up to $40 \mu \mathrm{g}$ polyA + RNA per lane. We attribute this to their low abundance because the average amount of rg-homologous RNA remaining in the polyA ${ }^{+}$ fraction would be less than 0.3 copy per cell. Moreover, if these poly $^{+}$transcripts were randomly nicked at sites $5^{\prime}$ to the position of the rg probe sequences, the amount of intact RNA would be even less. In contrast, the technique of nuclease protection is less reliant on the presence of intact RNA because only a short sequence is detected; in this case, intactness of the RNA is important for fractionation over oligo-dT but is essentially inconsequential thereafter.

If random nicking is the source of complex polyA- RNAs, then overlap of poly $\mathrm{A}^{+}$and poly $\mathrm{A}^{-}$complexity should have been observed in earlier complexity studies. One of the paradoxes is that the saturation hybridization studies showed additivity of the complexities due to polyA $\mathrm{A}^{+}$and polyA- RNA populations; this observation led to the conclusion that the 2 populations are distinct. However, sequences present at 10 -fold lower concentration than those detected by standard saturation hybridization (usually $1-0.1$ copies per cell) would have gone undetected in the above experiments. Therefore, if $90 \%$ of molecules encoding a long polyA ${ }^{+}$RNA were nicked during isolation, those sequences $5^{\prime}$ to the point of cleavage would not be detected as polyA $^{+}$RNA. If the long brain-specific sequences are already rare compared to housekeeping mRNAs, as suggested (Milner and Sutcliffe, 1983), they would be even more difficult to detect. This would be particularly important if the majority of molecules were broken, causing them to be much more abundant in the polyA- fraction, as is the case for the rg clones studied here.

Similarly, complexity studies in which cDNA was used could be biased by the presence of broken molecules. Again, insuffi-
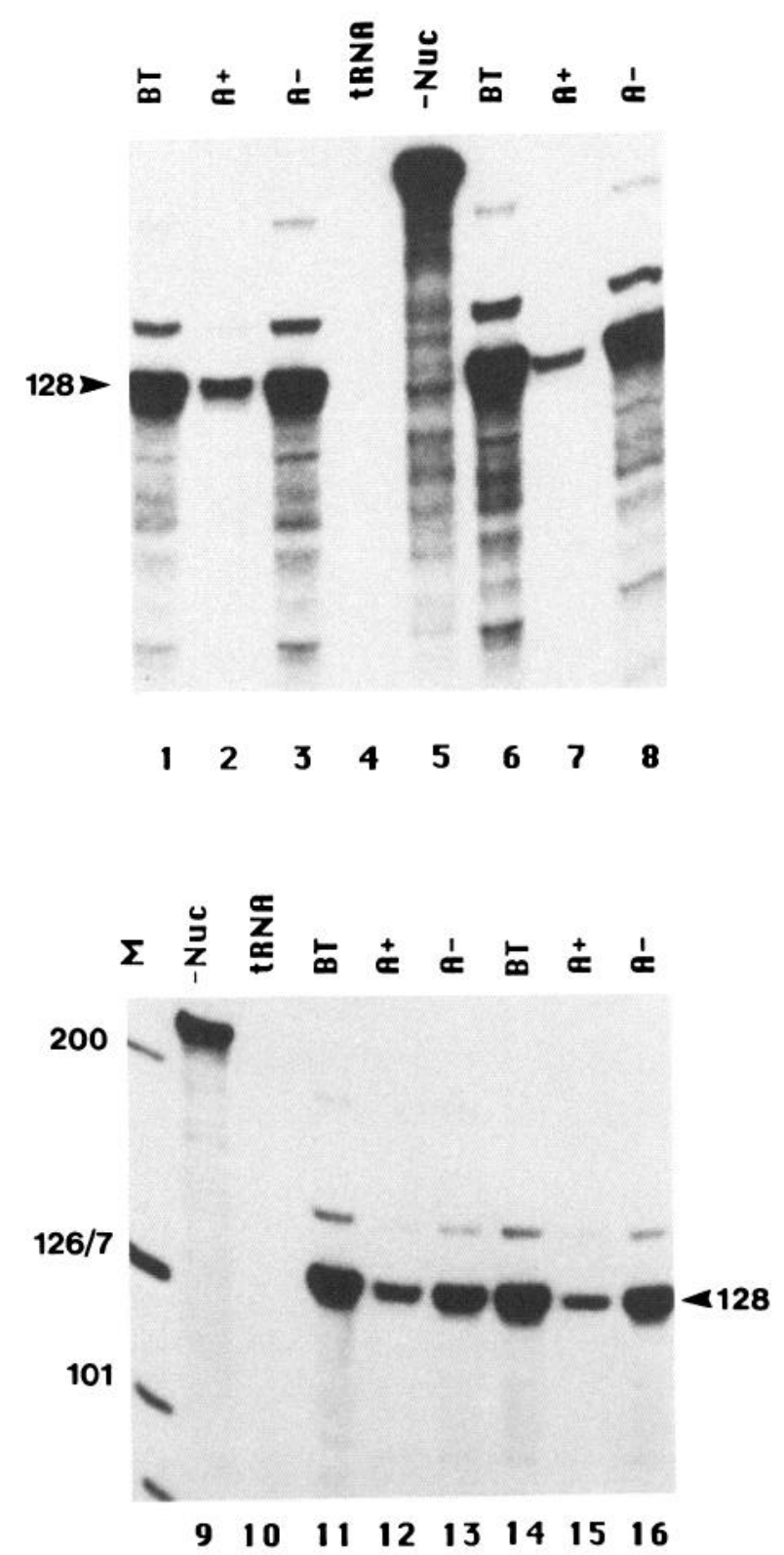

Figure 4. The majority of sodium channel sequences fractionate as polyA- RNA. Lanes 1-3, RNA prepared by isolation protocol 3 (see Materials and Methods); lanes 6-8. RNA prepared by protocol 4; lanes 11-13, RNA prepared by a modification of the Chirgwin method (Cooperman et al., 1987)-this RNA was a gift of S. Cooperman and G. Mandel, and identical preparations demonstrated intact 9.5-kb sodium channel mRNA on Northern blots (Cooperman et al., 1987); lanes 1416. RNA prepared by isolation protocol 1 (this RNA was a gift of T. Wood and A. Tobin). Lanes $1,6,11$, and 14 contain $5 \mu \mathrm{g}$ total rat brain RNA; lanes 2 and 7 contain $0.1 \mu \mathrm{g}$ ( 1 tissue equivalent) polyA+ RNA; lanes $3,8,13$, and 16 contain $5 \mu \mathrm{g}$ (1 tissue equivalent) polyA- RNA; lanes 12 and 15 contain $0.2 \mu \mathrm{g}$ ( 2 tissue equivalents) polyA $\mathrm{A}^{+} \mathrm{RNA}$. All polyA $^{+}$and polyA $\mathrm{A}^{-}$fractions were prepared by 2 cycles over oligo-dT cellulose. $E$. coli $t$ RNA was added to each sample to give a final mass of $50 \mu \mathrm{g}$. Lanes 4 and $10,50 \mu \mathrm{g} t \mathrm{RNA}$; lanes 5 and 9 , full-length sodium channel probe in the absence of nuclease digestion; $M$, size markers. The sodium channel probe protects a major 128 -nucleotide band representing $5^{\prime}$ untranslated and coding sequences, a 188-nucleotide band representing protection of the RNA precursor, and a band of approximately 150 nucleotides, which presumably represents a processing intermediate (Cooperman et al., 1987). In the upper panel, significant degradation of the probe has resulted in a high background of smaller bands. 


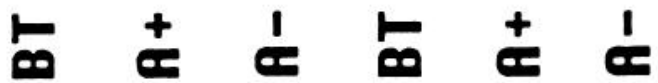

28s

18s
Figure 5. Detection of sodium channel message in various RNA fractions by Northern analysis. Lanes 1-3, RNA prepared by isolation protocol 3 (see Materials and Methods); lanes 4-6, RNA prepared by protocol 4 . Lanes 1 and 4, $25 \mu \mathrm{g}$ total brain RNA; lanes 2 and $5,5 \mu \mathrm{g}(10$ tissue equivalents with respect to lanes $1,3,4$, and 6 ) polyA $\mathrm{A}^{+}$ brain RNA ( 2 cycles of oligo-dT); lanes 3 and $6,25 \mu \mathrm{g}$ polyA- brain RNA (2 cycles). A 9.5-kb sodium channel band is clearly detected in total or polyA ${ }^{+}$ RNA, but not in the polyA- fraction. The location of $28 \mathrm{~s}$ and $18 \mathrm{~s}$ ribosomal RNA marker is shown. cient numbers of overlapping molecules would erroneously indicate distinct RNA populations.

In order to determine if long RNAs are nicked during preparation, we examined several different fractionated RNA preparations for the presence of sodium channel transcripts. Sodium channel message is known to be a $9.5-\mathrm{kb}$ poly $\mathrm{A}^{+}$message, which might be expected to fractionate like other long brain-specific RNAs. The results indicated that, independent of the isolation method, a sequence of this length is indeed so fragile that a major proportion ( $90 \%)$ of molecules are no longer full length after fractionation. The remaining $10 \%$ of intact sodium channel message was sufficient in quantity to yield a discrete $9.5-\mathrm{kb}$ band on Northern blots of polyA ${ }^{+}$RNA. It is apparent that Northern blots may not be a reliable method for quantitating long mRNAs, particularly because the degree of nicking may vary between RNA preparations. In contrast, as shown in Figure 3, a 2-kb mRNA (tyrosine hydroxylase) fractionated almost entirely into the poly $\mathrm{A}^{+}$fraction, as assayed by nuclease protection using a probe for the $5^{\prime}$ end.

Chaudhari and Hahn (1983) reported that the polysomal RNA complexity in mouse brain almost doubles from birth to adulthood. They attributed this increase to the expression of poly $\mathrm{A}^{-}$ RNAs, because by their measurements, essentially all the polyA ${ }^{+}$ diversity found in the adult is already present at birth. Similar results for polyA $\mathrm{A}^{+}$accumulation were seen in developing rat brain (Kaplan and Finch, 1982). Both rg13 and rg100 are induced 8-10-fold from E20 to adulthood and are representative of those developmentally regulated RNAs observed in the complexity measurements of Hahn and colleagues (Chaudhari and Hahn, 1983; Hahn et al., 1983). Therefore, if the rg clones really represent poly $\mathrm{A}^{+} \mathrm{RNAs}$, this suggests that the postnatal increase in total RNA complexity is due to the new or increased expression of a class of poly $\mathrm{A}^{+}$RNAs that are more labile than those expressed prenatally, perhaps because they are consider- ably longer, rather than to the expression of a new class of poly $\mathrm{A}^{-}$ RNAs.

We cannot, however, rule out the possibility that the rg RNAs are truly bimorphic and are initially synthesized in both forms, or that the poly $\mathrm{A}^{+}$isoform is deadenylated via a regulated processing event. Nevertheless, our data are consistent with the loss of polyA tails by nicking of labile RNAs during isolation. If this is the case, the poly $\mathrm{A}^{-}$class of complex brain-specific RNAs may not exist, or at least not in the numbers previously proposed. In addition, if this population of labile RNAs does represent exceptionally long RNAs, current estimates of the number of postnatally expressed brain genes consequently may have to be revised.

Note added in proof: Harris and Sherbany (in press) have recently demonstrated that transcripts of clones derived from a poly $\mathrm{A}^{-}$cDNA library are actually present in both polyA ${ }^{+}$and polyA- RNA.

\section{References}

Adesnik M, Darnell JE (1972) Biogenesis and characterization of histone messenger RNA in HeLa cells. J Mol Biol 67:397-406.

Auffray C, Rougeon F (1980) Purification of mouse immunoglobulin heavy-chain messenger RNAs from total myeloma tumor RNA. Eur J Biochem 107:303-314.

Aviv H, Leder P (1972) Purification of biologically active globin messenger RNA by chromatography of oligothymidylic acid-cellulose. Proc Natl Acad Sci USA 69:1408-1412.

Bantle JA, Hahn WE (1976) Complexity and characterization of polyadenylated RNA in the mouse brain. Cell 8:139-150.

Bantle JA, Courchesne CL, Couch M (1980) Complexity and complexity overlap in mouse liver polyadenylated and nonadenylated messenger RNA fractions. Biochem Biophys Res Commun 95:1710 1721.

Brilliant MH, Sueoka N, Chikaraishi DM (1984) Cloning of DNA corresponding to rare transcripts of rat brain: evidence of transcriptional and post-transcriptional control and of the existence of nonpolyadenylated transcripts. Mol Cell Biol 4:2187-2197. 
Brown IR, Church RB (1972) Transcription of nonrepeated DNA during mouse and rabbit development. Dev Biol 29:73-84.

Chaudhari N, Hahn WE (1983) Genetic expression in the developing brain. Science 220:924-928.

Chikaraishi DM (1979) Complexity of cytoplasmic polyadenylated and nonpolyadenylated rat brain ribonucleic acids. Biochemistry 18: 3249-3256.

Chikaraishi DM, Deeb SS, Sueoka N (1978) Sequence complexity of nuclear RNAs in adult rat tissues. Cell 13:111-120.

Chikaraishi DM, Brilliant MH, Lewis EJ (1983) Cloning and characterization of rat brain-specific transcripts: rare, brain-specific transcripts and tyrosine hydroxylase. Cold Spring Harbor Symp Quant Biol 48:309-318.

Chirgwin JM, Przybyla AE, MacDonald RJ, Rutter WJ (1979) Isolation of biologically active ribonucleic acid from sources enriched in ribonuclease. Biochemistry 18:5294-5299.

Church RB, Schultz GA (1974) Differential gene activity in the preand postimplantation mammalian embryo. Curr Top Dev Biol 8: 179-202.

Cooperman SS, Grubman SA, Barchi RL, Goodman RH, Mandel G (1987) Modulation of sodium-channel mRNA levels in rat skeletal muscle. Proc Natl Acad Sci USA 84:8721-8725.

Deeb SS (1983) Sequence complexity of nuclear RNA in brain sections of the sheep. Cell Mol Biol 29:113-119.

Gedamu L, Dixon GH (1976) Purification and properties of biologically active rainbow trout testis protamine mRNA. J Biol Chem 251 : 1455-1463.

Grady LJ, Campbell WP, North AB (1979) Nonrepetitive DNA transcription in normal and regenerating rat liver. Nucleic Acids Res 7: 259-269.

Grady LJ, Campbell WP, North AB (1981) Sequence diversity of nuclear and polysomal polyadenylated and nonpolyadenylated RNA in normal and regenerating rat liver. Eur J Biochem 115:241-245.

Grouse L, Chilton M-D, McCarthy BJ (1972) Hybridization of ribonucleic acid with unique sequences of mouse deoxyribonucleic acid. Biochemistry 11:798-805.

Grouse LD, Nelson PG, Omenn GS, Schrier BK (1978a) Measurements of gene expression in tissues of normal and dystrophic mice. Exp Neurol 59:470-478.

Grouse LD, Schrier BK, Bennett EL, Rosenzweig MR, Nelson PG (1978b) Sequence diversity studies of rat brain RNA: effects of environmental complexity on rat brain RNA diversity. J Neurochem 30:191-203.

Hahn WE, Laird CD (1971) Transcription of nonrepeated DNA in mouse brain. Science 173:158-161.

Hahn WE, Chaudhari N, Beck L, Wilber K, Peffley D (1983) Genetic expression and postnatal development of the brain: some characteristics of nonpolyadenylated mRNAs. Cold Spring Harbor Symp Quant Biol 48:465-475.

Harris DA, Sherbany AA (in press) Cloning of nonpolyadenylated RNAs from rat brain. Mol Brain Res, in press.

Hitti YS, Deeb SS (1984) Complexity of polysomal RNA in sheep brain sections and other organs. Cell Mol Biol 30:169-174.
Houdebine LM (1976) Absence of poly(A) in a large part of newly synthesized casein mRNAs. FEBS Lett 66:110-113.

Hunter T, Garrels JI (1977) Characterization of the mRNAs for $\alpha$-, $\beta$ - and $\gamma$-actin. Cell 12:767-781.

Ilaria R, Wines D, Pardue S, Jamison S, Ojeda SR, Snider J, Morrison MR (1985) A rapid microprocedure for isolating RNA from multiple samples of human and rat brain. J Neurosci Meth 15:165-174.

Kaplan BB, Finch CE (1982) The sequence complexity of brain ribonucleic acids. In: Molecular approaches to neurobiology (Brown IR, ed), pp 71-98. New York: Academic.

Kaplan BB, Gioio AE (1986) Diversity of gene expression in goldfish brain. Comp Biochem Physiol B 83:305-308.

Kaplan BB, Schachter BS, Osterburg HH, de Vellis JS, Finch CE (1978) Sequence complexity of polyadenylated RNA obtained from rat brain regions and cultured rat cells of neural origin. Biochemistry 17:55165524.

Kaufmann Y, Milcarek C, Berissi H, Penman S (1977) HeLa cell poly(A) ${ }^{-}$mRNA codes for a subset of poly(A) ${ }^{+}$mRNA-directed proteins with an actin as a major product. Proc Natl Acad Sci USA 74: $4801-4805$.

Lee D, Castro CE, Jagodzinski LL, Sevall JS (1979) Functional significance of rat liver nonhistone protein-DNA interactions: RNA hybridization of protein-bound DNA. Biochemistry 18:3160-3165.

Lewis EJ, Tank AW, Weiner N, Chikaraishi DM (1983) Regulation of tyrosine hydroxylase mRNA by glucocorticoid and cyclic AMP in a rat pheochromocytoma cell line: isolation of a cDNA clone for tyrosine hydroxylase mRNA. J Biol Chem 258:14632-14637.

Milner RJ, Sutcliffe JG (1983) Gene expression in rat brain. Nucleic Acids Res 11:5497-5520.

Morrison MR, Brodeur R, Pardue S, Baskin F, Hall CL, Rosenberg RN (1979) Differences in the distribution of poly $(A)$ size classes in individual messenger RNAs from neuroblastoma cells. J Biol Chem 254:7675-7683.

Nadin-Davis S, Mezl VA (1983) Distribution of rat $\alpha$-lactalbumin and casein mRNA between polyadenylated and nonpolyadenylated RNA. Can J Biochem Cell Biol 61:353-362.

Noda M, Ikeda T, Kayano T, Suzuki H, Takeshima H, Kurasaki M, Takahashi H, Numa S (1986) Existence of distinct sodium channel messenger RNAs in rat brain. Nature 320:188-192.

Ouellette AJ, Ordahl CP (1981) Extensive homology between poly(A)containing mRNA and purified nominal poly(A)-lacking mRNA in mouse kidney. J Biol Chem 256:5104-5108.

Perrone Capano C, Gioio AE, Giuditta A, Kaplan BB (1986) Complexity of nuclear and polysomal RNA from squid optic lobe and gill. J Neurochem 46:1517-1521.

Shackleford GM, Varmus HE (1987) Expression of the proto-oncogene int- 1 is restricted to postmeiotic male germ cells and the neural tube of mid-gestational embryos. Cell 50:89-95.

Van Ness J, Maxwell IH, Hahn WE (1979) Complex population of nonpolyadenylated messenger RNA in mouse brain. Cell 18:13411349. 